${ }^{24}$ Adamopoulous, D A, Loraine, J A, and Dove, G A, Fournal of Obstetrics and Gynaecology of the British Commonwealth, 1971, 78, 62.

${ }^{25}$ Thiissen, J H H, in De Bussy 18th Year Book of Cancer Research in The Netherlands, p 171.1968.

${ }^{26}$ Procope, B J, and Adlercrentz, H, in Frontiers of Hormone Research, ed P A Van Keep, and C Lauritzen. Basel, Karger, 1975.

27 Thiissen, J H H, et al, in Frontiers of Hormone Research, ed P A Van Keep and C Lauritzen. Basel, Karger, 1975.

${ }^{28}$ Siiteri, P K, Grodin, J M, and MacDonald, P C, in Proceedings of the Conference on the Menopause and Ageing, Hot Springs, Arkansas, 1971.

${ }^{29}$ Barlow, J J, Emerson, E, and Saxena, B N, New England Medical fournal, 1969, 280, 633.

${ }^{30}$ Saez, J M, et al, fournal of Endocrinology, 1972, 55, 41.
${ }^{31}$ McDonald, P C, Van de Wiele, R M, and Liberman, L S, American Fournal of Obstetrics and Gynecology, 1963, 86, 1 .

32 Nimrod, A, and Ryan, R J, fournal of Clinical Endocrinology and Metabolism, 1975, 40, 367 .

33 Inguilla, W, and Forleo, R, in Endocrinologic and Morphologic Correlations of the Ovary, ed W Inguilla and R B Greenblatt. p 82. Springfield, Charles C Thomas, 1969.

${ }^{34}$ Studd, J, Chakravarti, S, and Oram, D, in press.

${ }^{35}$ Moore, B, Gustafson, R, Studd, J, Current Medical Research and Opinion, 1975, 3, Suppl No 3, p 42.

${ }^{36}$ Studd, J, Chakravarti, S, and Oram, D, Postgraduate Medical fournal, 1976, 52, 60.

\title{
Observations on electrocardiogram and plasma catecholamines during dental procedures: the forgotten vagus
}

\author{
PETER TAGGART, ROBIN HEDWORTH-WHITTY, MALCOLM CARRUTHERS, \\ PETER D GORDON
}

British Medical fournal, 1976, 2, 787-789

\begin{abstract}
Summary
Emotional stress is conventionally considered to be associated with tachycardia and enhanced sympathetic activity. The electrocardiogram and plasma catecholamine and lipid concentrations were observed in 21 young healthy women undergoing dental procedures. Ten of these received premedication with the beta-blocking agent oxprenolol and 11 with a placebo, administered on a double-blind randomised basis. Mild tachycardia occurred in the placebo group a few minutes before and a few minutes after dentistry, but there was a reduction in heart rate immediately before and during the procedure. The pattern was similar in the group who received oxprenolol, though the heart rates at each stage were lower. Plasma adrenaline concentrations were much higher in the samples taken during the procedure than in those taken shortly before and after it. Plasma noradrenaline and lipid concentrations remained unchanged.
\end{abstract}

A decrease in heart rate in the face of intense emotional arousal and an increased plasma adrenaline concentration suggest that the expectation or experience of pain may be associated with parasympathetic dominance despite greatly enhanced sympathetic activity.

\section{Introduction}

Emotional stress is conventionally considered to be associated with enhanced sympathetic activity and a tachycardia. Tachycardia associated with increased plasma concentrations of adrenaline or noradrenaline, or both, has been shown to occur at times in response to emotional stress. ${ }^{1-4}$

Nevertheless, among the increasing number of reports

\footnotetext{
Cavendish Medical Centre, London W1

PETER TAGGART, MD, MRCP, physician and honorary senior lecturer, Middlesex Hospital

ROBIN HEDWORTH-WHITTY, MD, MRCP, cardiologist

St Mary's Hospital, London W2

MALCOLM CARRUTHERS, MD, MRCPATH, senior lecturer in chemical pathology

PETER D GORDON, LDS, RCS, dental officer to the nursing staff
}

implicating the autonomic system as the mediator of physiological effects induced by emotion ${ }^{5}$ little mention has been made of the parasympathetic system. We have become increasingly aware that certain emotions, particularly those during the witness, expectation, or actual experience of pain, may be associated with a bradycardia, or at least an absence of tachycardia, despite obviously intense behavioural evidence of arousal and increased circulating catecholamines. ${ }^{6}$ This would suggest parasympathetic dominance despite greatly enhanced sympathetic activity.

We report here a study designed to test this theory since we believe that if correct it may have important application to the management of people with coronary heart disease.

\section{Subjects and methods}

The electrocardiograms (ECGs) and plasma catecholamine and lipid concentrations were observed in a group of young women undergoing routine dental procedures after receiving either a placebo or the beta-blocking agent oxprenolol. This was selected as representing a common experience in which the fear of pain constituted the emotional challenge.

Twenty-two members of the nursing staff of the Middlesex Hospital volunteered to participate in the study and were allocated to one of two groups. The subjects were matched for age, and although one was later excluded from analysis owing to a technical failure of ECG recording, the ages of each group remained comparable. The mean age ( $\pm S D$ ) was $27 \pm 6.3$ years in the 11 patients in the placebo group and $27 \pm 5.8$ years in the 11 patients in the oxprenolol group. All had apparently normal hearts, and none had any obvious psychiatric reason to disqualify them from participating in the study. Nurses were chosen because previous observations had suggested that young women may show a more labile emotional response and because they were a homogeneous group.

Medication-Each subject was given either a placebo or a single oral dose of $40 \mathrm{mg}$ oxprenolol, administered on a double-blind randomised basis, 45 minutes before entering the surgery.

ECGs were recorded ${ }^{7}$ using the miniaturised Recard system (Kimal Scientific Products Ltd, Hillingdon, Middlesex). Two chest electrodes were connected to the subject to approximate to a V5 position.

Blood samples were taken by venepuncture a few minutes before the start of the procedure, during the procedure, and about 10 minutes after completion. Samples were collected, preserved, and analysed for catecholamines according to methods described. ${ }^{8}$ Lithium sequestrine samples were similarly preserved for lipid estimations.

Dental procedure-All subjects had been patients of the dentist (PDG). The dental work carried out consisted of routine restorative procedures performed with both high-speed air-turbine equipment and low-speed handpieces. The local anaesthetic used was Citanest 
$3^{\circ}{ }_{0}$; felypressin (Octapressin) $0.03 \mathrm{IU} / \mathrm{ml}$ was chosen as the vasoconstrictor to avoid using either adrenaline or noradrenaline for local vasoconstriction. The use of self-aspirating syringes used with selfaspirating cartridges reduced the possibility of intravascular injection to a minimum.

Personnel-Two senior women medical students conducted the tests and nobody else other than the dentist and dental nurse were present.

Blood pressure-Blood pressure was not measured in the 22 nurses since we considered that to do so would compound the separate anxieties attendant on monitoring procedures. Cuff blood pressure and wrist pulse readings were, however, taken from another group of nine nurses of comparable ages undergoing similar procedures in the same surgery with the same dentist but without premedication and without ECG monitoring or blood samples.

Statistical methods-Plasma catecholamine concentrations show a positively skewed distribution in normal subjects. Accordingly nonparametric analysis was used. The Mann-Whitney $U$ test $^{9}$ was used to test the difference between the median values in the two groups of subjects and the Wilcoxon signed rank test to evaluate changes in values within each group. ${ }^{10}$ Parametric statistics were used for evaluating heart rates.

\section{Results}

Heart rates-The mean heart rates for the 11 subjects who received the placebo and the 10 subjects who received oxprenolol are shown in fig 1 . The heart rate fell significantly in both groups during the procedure (administration of local anaesthetic and drilling) from the rates observed about 10-15 minutes before and after. This reduction in heart rate occurred while the subjects were sitting in the dental chair before any intervention, it persisted throughout the procedure, and

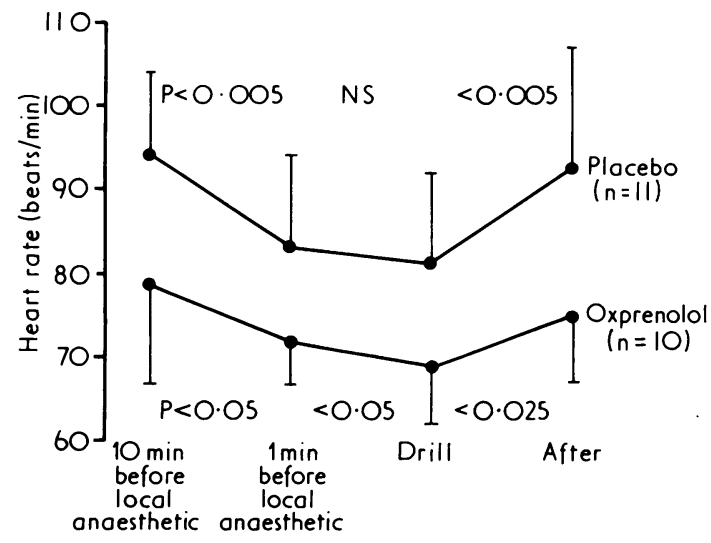

FIG $1-$ Mean heart rates $( \pm S D)$ in 21 women undergoing dental surgery. Ten had received oral dose of $40 \mathrm{mg}$ oxprenolol and 11 a placebo.

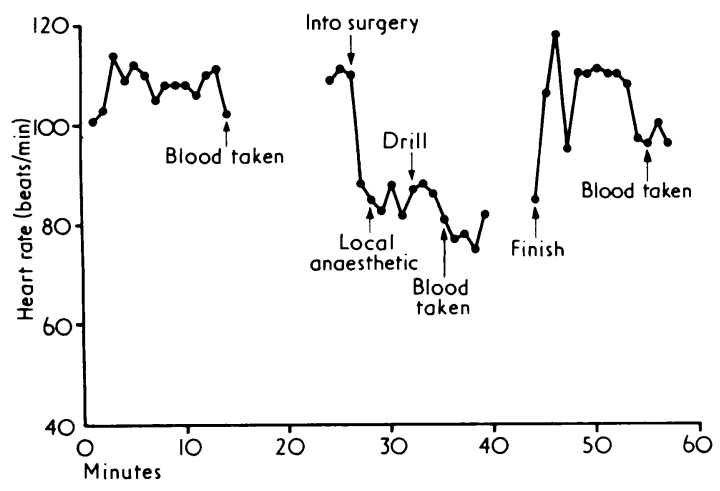

FIG 2-Heart rate in 23-year-old woman who had received placebo. Heart rate fell on entering the dental surgerythat is, before the procedure-and an abrupt increase with overshoot occurred after the procedure. the rate rose abruptly afterwards. The heart rates in the group taking oxprenolol were lower at each of the four stages (all significant at the $1 \%$ level). Data from two individual subjects are presented in figs 2 and 3.

Plasma catecholamines-In both groups plasma adrenaline concentrations were significantly higher during the procedure than shortly beforehand (fig 4). A significant reduction was observed in the placebo group in samples taken a few minutes afterwards, al though these were still considerably above normal, while the oxprenolol group sustained increased values. Although median concentrations before, during, and after the procedure in the placebo group were greater than in the oxprenolol group the difference was significant only in samples taken during the procedure $(P<0.05)$. Plasma noradrenaline concentrations were not apparently influenced and remained within the normal range throughout. The differences between the median values in the two groups failed to reach significance at the $5^{\circ}{ }_{0}$ level. Plasma-free fatty acid concentrations (FFA) remained normal and apparently uninfluenced by the procedure. We made no formal attempt to measure the degree of emotional arousal in either group.

Blood pressure-Little difference was apparent at any stage in the blood pressure recordings obtained from the nine nurses studied without either ECG monitoring or premedication.

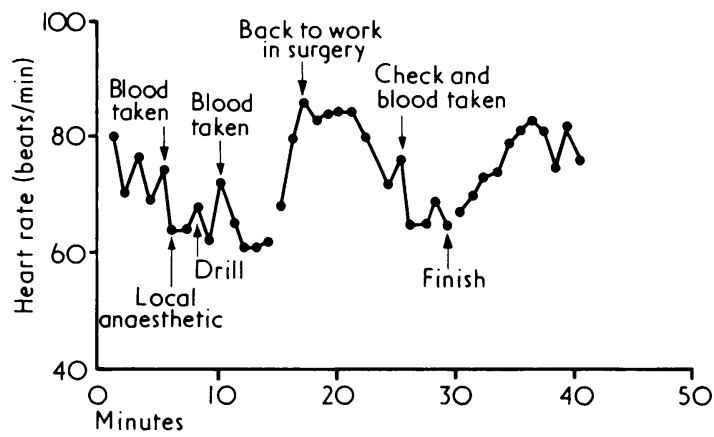

FIG 3-Heart rate in 21-year-old dental nurse who had received oxprenolol. Heart rate was lower than that of patient in fig 2. After dentistry her heart rate increased abruptly. When she was unexpectedly recalled for a further check her heart rate decreased and then increased again at the end.

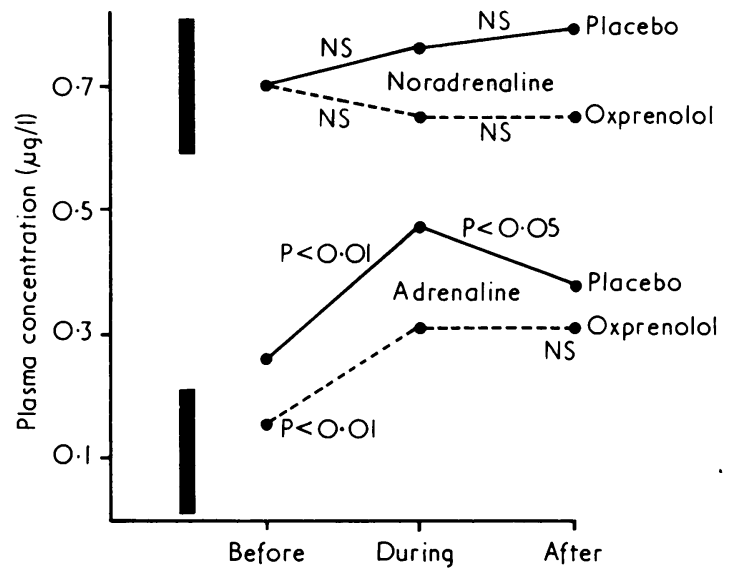

FIG 4-Median plasma noradrenaline and adrenaline concentrations in 21 women undergoing dental procedures. Shaded areas represent normal ranges. NS $=$ Not significant.

\section{Discussion}

This study has shown a fall in heart rate to near resting or tranquil levels during the height of an emotional challenge in the face of increasing anxiety and a rising plasma adrenaline concentration. These findings suggest intense parasympathetic activity overriding greatly enhanced sympathetic activity. 
Although the heart rates were significantly lower during the procedure in those subjects who had received oxprenolol than in those who had received placebo the difference was small. This again supports the suggestion of strong vagal activity, since if the increased sympathetic activity was exerting only a minor influence on net heart rate as a result of parasympathetic dominance then only a small difference in heart rate would be expected as a consequence of beta-blockade. The lack of any important change in blood pressure in the subsidiary group suggests that reflex slowing of the heart rate was an unlikely alternative to a more direct emotionally induced effect.

Interest in equating different emotions with a differential secretion of adrenaline and noradrenaline ${ }^{11-13}$ may have diverted attention from the parasympathetic system. For example, Edmondson et al, ${ }^{14}$ reporting a study on dental patients, attributed a mean heart rate of $88 / \mathrm{min}$ during surgery, which was slightly higher than resting rates, to sympathetic activity. As in our study, their subjects showed grossly raised plasma adrenaline concentrations. Most of our previous observations on emotions of different types and intensities led us to expect tachycardia of about $140-200 / \mathrm{min}$ at such adrenaline concentrations. The possible exception is pain. We have studied young healthy people watching a film depicting an unusually graphic display of pain and the expectation of pain. ${ }^{6}$ The heart rates of most subjects, particularly the women, fell appreciably, often to very low levels (below $60 / \mathrm{min}$ ), despite a concomitant increase in urinary adrenaline secretion. Vasovagal syncope was not unusual in people watching that particular sequence.

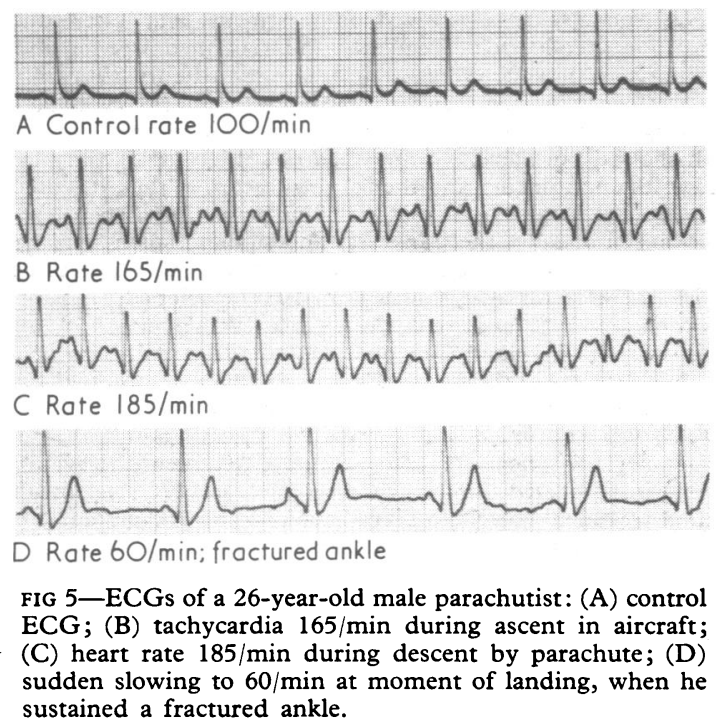

Vasovagal syncope in response to acute severe pain is well known. But we know of no report of the ECG and plasma catecholamine concentrations in such circumstances. One person whom we monitored while making a parachute descent fractured his ankle on landing, when within a few seconds his heart rate decreased abruptly from 185 to $60 / \mathrm{min}$ (fig 5), despite a plasma adrenaline concentration in a sample taken synchronously with the fall in heart rate that was greatly increased. The plasma noradrenaline concentration was unchanged. Since there was a delay of about two minutes between the injury (and reduction in heart rate) and the experience of pain, it is interesting to compare this single observation with those in our dental patients in whom the initial fall in heart rate, occurred not during but before the surgical procedures. This might suggest that it is not only the experience or witnessing of pain but the expectation of it that is important in inducing vagal activity.
The once held view that the sympathetic and parasympathetic systems operated by a reciprocal "shut on/shut off" mechanism is no longer tenable, and it has even been shown in animals that the effect of vagal stimulation may be potentiated by sympathetic stimulation. ${ }^{15}$ It has been appreciated for some time that depressor responses, often accompanied by vagal bradycardia, may be elicited from cortical autonomic areas ${ }^{16}$ and particularly from stimulation of the anterior cingulate gyrus, ${ }^{17}$ suggesting a possible mechanism for the emotionally induced parasympathetic activity we have proposed. Much has been written on the hazard of vasovagal syncope in dentistry, ${ }^{1-23}$ which has been variously attributed to posture and "fear, pain or other emotions." ${ }^{24}$

The physiological events that we have described in clinically well young subjects may have a bearing on the management of patients with ischaemic heart disease. While probably unimportant to most people with normal hearts, the combination of altered perfusion gradients, ${ }^{25}$ low heart rate, and enhanced sympathetic activity would in certain people be expected to facilitate the development of arrhythmias. The suggestion that the bradycardia observed in about a quarter of patients within the first hour after myocardial infarction ${ }^{26}$ is attributable to neuroreceptors in the territory of the right coronary artery ${ }^{27}$ or left coronary artery ${ }^{28}$ lacks proof. Possibly the old-fashioned treatment of sedation, analgesia, and tranquillity, so much in danger of being forgotten, ${ }^{29}$ has its roots founded partly in the simple prevention of pain.

We would like to thank Dr Walter Somerville, department of cardiology, Professor Eric Neil, department of physiology, and Dr O P Dinnick, department of anaesthetics, Middlesex Hospital, for their help in the preparation of this manuscript. We are grateful also to Ciba Laboratories for financial support, to Astra Chemicals for supplies of Citanest cartridges and syringes, to the nurses who volunteered to take part in the study, and to Sister Ruth Thomson for preparing the illustrations.

\section{References}

1 Taggart, P, Gibbons, D, and Somerville, W, British Medical fournal, $1969,4,130$.

2 Taggart, P, Carruthers, M, and Somerville, W, Lancet, 1973, 2, 341.

3 Taggart, $\mathrm{P}$, and Carruthers, M, Lancet, 1971, 1, 363.

4 Taggart, $\mathbf{P}$, et al, in preparation.

5 Levi, L (editor), Society, Stress and Disease. London, Oxford University Press, 1971.

6 Carruthers, M, and Taggart, P, British Medical fournal, 1973, 3, 384.

${ }^{7}$ Hirschberg, H, Cappelen, C, jun, and Wien, A, in Transactions of the Scandinavian Conference of Biomedical Engineering, Oslo, 1971

8 Carruthers, M, et al, Lancet, 1970, 2, 62.

${ }^{9}$ Mann, H B, and Whitney, D R, Annals of Mathematics and Statistics, $1947,18,50$

${ }^{10}$ Campbell, R C, Statistics for Biologists. London, Cambridge University Press, 1967.

${ }^{11}$ Funkenstein, D H, King, S H, and Drolite, M, Psychosomatic Medicine, 1954, 16, 404

12 Von Euler, US, Clinical Pharmacology and Therapeutics, 1964, 5, 398.

13 Frankenhaeuser, $M$, in Society, Stress and Disease, ed L Levi, 22. London, Oxford University Press, 1971.

14 Edmondson, H D, Roscoe, B, and Vickers, M D, British Medical fournal, $1972,4,7$.

${ }^{15}$ Levy, M N, and Zieske, H, Circulation Research, 1969, 24, 303.

16 Folkow, B, and Neil, E, Circulation, London, Oxford University Press, 1971.

17 Breggin, P R, fournal of Nervous and Mental Diseases, 1964, 139, 558.

18 Bourne, J G, Lancet, 1957, 2, 499.

19 Bourne, J G, Lancet, 1966, 1,879.

20 Bourne, J G, Anaesthesia, 1970, 25, 473.

${ }^{21}$ Hannington-Kiff, J G, Dental Practitioner, 1969, $20,2$.

22 Ryder, W, Anaesthesia, 1970, 25, 46.

${ }^{23}$ Tomlin, P J, Anaesthesia, 1974, 29, 551.

24 Green, R A, and Coplans, M P, Anaesthesia and Analgesia in Dentistry, p 167. London, Lewis, 1973.

${ }^{25}$ Hedworth-Whitty, R B, Honstey, E, and Abrahams, A S, Cardiovascular Research, 1970, 4, 301.

${ }^{26}$ Adgey, A A J, et al, Lancet, 1968, 2, 1097.

27 Juhasz-Nagy, A, and Szentivanyi, M, Archives Internationales de Pharmaeodynamie et de Thérapie, 1961, 131, 39.

${ }^{28}$ Frink, R J, and James, T N, American fournal of Physiology, 1971, 221, 1964.

${ }^{29}$ Nixon, P G F, et al, Lancet, 1968, 1, 726 